\title{
0 intelectual modernista como artista: Rubén Darío
}

Susana Zanetti Tradução de Alexandre Massella

J oséM artí eR ubén $\mathrm{D}$ arío presidiram as duas princi pais etapas do modernismo, primeiro movimento literário articulado entre os artistas do mundo hispano-americano, que logrou igual projeção na Espanha graças a encontros, revistas, troca de livros, artigos críticos recíprocos etc. Ambos encarnaram a rápida transformação do homem de letras do século XIX. Considerado do ângulo da condição intelectual, esse homem mudou de ênfase, passando do privilégio dado ao político - o dever com a independência de Cubaésilenciado no poetaJ osé M artí - à afirmação do saber da arte, sustentada pelo poeta R ubén $D$ arío como único respaldo para intervir no mundo das idéias. D essa nova perspectiva, D arío instaurou com vigor sua polêmica autoridade, atuando com o peso de sua variada presença institucional e discursiva (em gêneros, centros nacionais etc.), para insistir na primazia do trabal ho intelectual fundado em todas as possibilidades da palavra; ele dirá que "muitas vezes a música éa idéia" ou quea idéia está na forma.

Em 1895 D arío publicou o necrológio de M artí no diário La N ación, de BuenosAires, quase um manifesto dessa inflexão, inscrito no difícil eincerto processo de constituição do intelectual crítico e nas demandas de autonomia estética que singularizava todos os modernistas.

Esse notável manifesto contra a submissão do artista aos imperativos da nação foi publicado em um meio hispano-americano que, ou celebrava o heroísmo de M artí, ou silenciava o tema em nome das boas relações 
1.N ecrológio incluído em Darío ([1896] 1952, p. 195). [A data entre colchetes referese à edição original da obra, indicada apenas naprimeiravezem que a obraécitada. $N$ as de mais, indica-se apenas a edição utilizada pelo autor (N.E.).] com a Espanha e os Estados U nidos, invasores de Cuba e Porto Rico. 0 manifesto discute e rechaça a submissão do artista à política e ao Estado, em uma etapa em que predominavam os governos fortes, rodeados por uma camada dirigente de raiz positivista, concentrada em dar soluções à "questão nacional"; exigia-se, assim, que os textos esboçassem uma identidade integradora que incluísse e controlasse a mobilidade populacional provocada pela modernização. D arío assim se expressa em um dos parágrafos: "O s tambores da mediocridade, os clarins do patriotismo entoarão celebrando a glória política do Apolo armado de espadas e pistolas, que foi derrubado, sacrificando sua vida, que teria sido preciosa à $\mathrm{H}$ umanidade, à Arte e ao verdadeiro triunfo da América, combatendo entre o negro Guillermón e o general M artínez C ampos!"1.

Embora não 0 manifestasse sistematicamente por razões de espaço, o papel dariano é indicativo daquele al cançado por seus pares modernistas, ainda que possamos identificar no movimento mudanças e diferenças na escrita e nas escolhas estéticas e ideológicas, dada sua realização em um território extenso e em um período amplo (1882-1910). É claro, porém, que $D$ arío se tornará o líder desse grupo cultural que baseava a visibilidade e a autoridade de seu discurso literário e intelectual, de firmes convicções cosmopolitas, na autodefinição como artista moderno. U m deles, M anuel G utiérrez N ájera, assim se expressa: "H oje os tempos mudaram. A literatura é na Europa uma carreira plena, tão disciplinada como a carrei ra militar [...]. O s escritos, como qualquer outra mercadoria, estão sujeitos à lei da oferta e da procura" (N ájera, 1881).

Recordemos que D arío (1867-1916) nasceu na N icarágua, em um âmbito cultural e social arcaico. Integrante de setores médios modestos, com apenas quinze anos iniciou na imprensa de $M$ anágua (que publicou vários de seus poemas) uma carreira caracterizada pela firme decisão de distanciar-se das práticas provincianas, carreira levada adiante primeiro nas cidades centro-americanas vizinhas e, logo em seguida, nas hispanoamericanas mais modernas, sempre em busca de um espaço propício para transcender o regional.

Seu deslocamento rumo ao sul, mais precisamente ao Chile em 1886, indicava também um deslocamento das experiências estéticas do primeiro modernismo, em especial as mexicanas de $M$ anuel Gutiérrez $N$ ájera (1859-1895), com suas crônicas, seus Cuentos frágiles (1883) e a revista Azul (1894-1896), fundada com C arlos Díaz D ufoo. Essas experiências foram compartilhadas por muitos outros, entre os quais se destacaram 0 
colombiano José Asunción Silva (1865-1896) e os poetas cubanos Julián del Casal (1863-1893) e José M artí (1853-1895) - Ismaelillo (1888), Versos sencillos (1891). D este último, convém ressaltar as "C rônicas norte-americanas", que constituíram textos fundamentais para avaliar a modernização dos Estados U nidos e seus efeitos na América Latina. O s textos centrados na literatura e na arte apresentavam para o mundo de língua espanhola a literatura anglo-americana (0 scar W ilde, Walt W hitman), em certos casos pela primeira vez.

$\mathrm{N}$ o C hile, os textos de $D$ arío trazem a marca de suas leituras das correntes artísticas francesas (um "galicismo mental", na definição de Juan Vale ra) ${ }^{2}$, com as quais revolucionou a prosa, dando nascimento, com Azul (1887), ao moderno conto espanhol eà ainda inédita críticaà nova figura dominante, o burguês, homem que, com sua vulgaridade e seu fascínio pelo dinheiro, condena 0 artista à marginalidade. Azul assinalou o início do modo pelo qual $D$ arío viria a afirmar o papel do artista e, nas discussões a respeito da sociedade e da cultura moderna, as formas de intervenção da arte.

A partir de 1893, fica evidente o aprimoramento de seu conhecimento da moderna literatura estrangeira, especial mente de parnasianos esimbolistas, conhecimento que, somado a seu precoce contato com o legado espanhol, está na base de sua renovação, possi bilitada também pela inserção de D arío nas cidades mais modernas da América espanhola. N esse mesmo ano, transferiu-se para Buenos Aires, onde se tornaria o principal cronista de La $\mathrm{N}$ ación, diário no qual trabalhou como correspondente até sua morte. "A República Argentina foi para mim um magnífico refúgio, em cuja capital, embora repleta de tráficos comerciais, havia uma tradição intelectual e um meio mais favorável ao desenvolvimento de minhas faculdades estéticas", dirá em H istoria de mis libros (1913).

Como os jovens escritores que se foram reconhecendo no epíteto de modernistas, a formação de $D$ arío foi praticamente de autodidata, tributária do incipiente desenvolvimento da indústria cultural e realizada fora dos setores ilustrados (setores que se beneficiaram de estudos regulares e que freqüentaram a universidade como al unos e professores). Embora não conseguissem se livrar da necessidade do favor político (cargos diplomáticos, no caso de $D$ arío) e do mecenato, os modernistas fizeram da inserção no mercado o instrumento de sua formação intelectual e de captação de um público para a arte, buscando independência (sobretudo $D$ arío) da tutela que pretendia encerrar o discurso no hispânico e/ ou no nacional. Submetidos ao emprego múltiplo e à rápida profissionalização, os modernistas fo-
2.Em 30 de junho de 1889, o romancista e crítico literário espanhol Juan Valera publica, na revista Azul, um longo e denso ensaio sobre D arío, apontando a excessiva ad esão do escritor à moderna literatura francesa, atitude que define como "galicismo mental". 
3. 0 Ateneo, inaugura do pouco antes da che gadadeD arío aBuenos Aires, incorporou-o em seguida como membro correspondente. ram responsáveis, embora não estivessem sozinhos, pela nova configuração do trabalho intelectual na América espanhola.

0 movimento entre as mesas de redação fundia-se com o dinamismo da moderna Buenos Aires. "A boemia foi uma imposição, não uma escolha", comenta Ángel Rama, pois todos foram "trabal hadores incan sáveis... capazes de alta produtividade" (Rama, 1985, p. 122). D arío sabia que, embora precisasse extrair o "ganha pão do tinteiro", esse pão trazia em si as boas (mas trabalhosas) relações com o Ateneu de Buenos Aires ${ }^{3}$ e com outros literatos consagrados. Em suas crônicas, seu lugar era quase sempre o dos destinatários, isto é, principalmente o público de Buenos Aires, mas visava mais além, já que ambicionava inserir-se no que chamaríamos a República M undial das L etras, ressaltando assim, da mesma forma que Gómez Carrillo e outros, um pertencimento múltiplo. Evidentemente, Darío não suportava as censuras de La Nación nem do poder político, como sucedia com outros intelectuais do período. É evidente também que as mudanças de tom e de tema dosaram seus zel os com o meio portenho: sua escrita transgressora apoiava-se em um cronista agressivo, irônico e, ao mesmo tempo, próximo, confidente elisonjeador.

M as suas simpatias e amizades inclinavam-se para os novos atores, socialistas, anarquistas, pintores, jornalistas, com os quais podia falar de suas inquietações:

Na cervejaria Luzio tínhamos o salão dos suíços, na M onti, um jardim grande como um lenço, na Aue's Keller - reservada para nós - , uma imensa mesa de carvalho maciço... O s comensais éramos, com Rubén D arío, Leopoldo L ugones, Roberto Payró, Eugenio Díaz Romero, o panamenho Darío Herrera, Armando Vasseur..., o basco Grandmontagne e, às vezes, o malogrado poeta C arlos 0 rtiz, 0 elegante Leopoldo Díaz ou o grave e bondoso Luis Berisso. D ois espíritos endemoninhados jamais faltavam: o terrível Alberto Ghiraldo e o abominável Pepe Ingenieros... (Galtier, 1973, p. 42).

Essa agitação durou poucos anos, abrindo caminho para aárdua trajetória de um poeta vigoroso, mas débil como homem, consumido pelo álcool desde muito jovem.

Em BuenosAires culminou o primeiro período de sua trajetória de escritor, com doislivros publicados em 1896. U m deles, Prosasprofanas, foi responsável pela profunda renovação da poesia espanhola: o texto "Palabras liminares", desse mesmo livro, audacioso para o meio literário da época, 
marcou o início de seus manifestos, verdadeiros atos de política cultural. D arío reiterava aí a definição de sua estética - eda do modernismo - , baseada na liberdade ena crítica das escolas literárias e do pensamento submetido a princípios irrevogáveis (princípios certamente próximos do positivismo e do naturalismo dominantes):

$\mathrm{N}$ ão tenho literatura "minha"... não pretendo balizar o rumo dos demais: minha literatura é minha em mim; quem seguir de maneira servil as minhas pistas perderá seu tesouro pessoal e, pajem ou escravo, não poderá ocultar divisa ou uniforme. Certa vez Wagner disse a Augusta H olmes, sua discípula: “Em primeiro lugar, não imite ninguém e, sobretudo, não imite a mim". Grandes palavras.

A ironia e o humor costumavam caracterizar as contínuasintervenções de D arío no mundo das idéias, mundo que percorria usando a crônica ou 0 comentário na imprensa, tematizando não só a arteea literatura, embora sua perspectiva privilegiasse os dotes de caráter estético. Essa atitude, típica dos modernistas, assumiu em $\mathrm{D}$ arío uma densidade pouco freqüente, graças ao desenvolvimento de temas e procedimentos que traziam em cena o refinamento, a propensão ao desdobramento das pretensões aristocráticas do artista moderno. A inclusão no "proletariado intelectual", porém, distanciava os modernistas do aristocratismo das elites sociais tradicionais e das posturas professorais e autoritárias. $\mathrm{N}$ a breve introdução a 0 piniones (1906), como em muitas outras ocasiões, D arío afirma: "N ão pretendo que os outros pensem como eu nem se manifestem como eu. Liberdade!, liberdade!, meus amigos, enão deixem que coloquem em vocêsuniforme de nenhum tipo".

M uitas vezes volúvel, disposto a zombar da afetação dosilustrados, $D$ arío elaborou um discurso e uma imagem de autor próximo ao leitor, "sentimental, sensível, sensitivo". Seu célebre poema "Yo soy aquel" (deum poeta sem dúvida vigoroso) éuma amostra de seu modo de se definir e de definir uma cosmovisão estruturada nessa paisagem de experiências conflitantes, próprias do artista moderno, que em seu caso suavizam as arestas da contradição, da prisão no antitético - no binarismo dogmático - , quebrado pelos nexos copulativos, que instalam a convivência do simultâneo em face dos subordinantes, junto às contínuas gradações sonoras, rítmicas e simbólicas. Um exemplo: 


\section{Literalmente: "emui-} to século XVIII emuito antigo/ emuito moderno, audaz, cosmopolita;/ com Hugo forte e com Verlaineambíguo,/ e uma sede de ilusões infinita" (N .T.).

5.La Nación, 21 de agosto de 1893. con H ugo fuerte y con Verlaine ambiguo,

y una sed de ilusiones infinita ${ }^{4}$.

Suas intervenções intelectuais assumiam outra envergadura, apresentadas, muitas vezes, como oblíquas tomadas de posição. Isso fica claro na escolha da figura de $\mathrm{N}$ ietzsche, em artigo que apresentava pela primeira vez o filósofo alemão ao mundo de fala hispânica. M as ele o fez no interior dos "raros", entre esses artistas modernos que são representados como uma ilusória confraria em apoio de suas postulações (cf. D arío, 1894). Foi justamente esse o outro livro importante do período de Buenos Aires: Los raros, coletânea de textos publicados em La N ación, esboça uma caleidoscópica argumentação para expressar concepções estéticas, sustentadas por uma galeria de retratos de artistas modernos (Poe, Verlaine, Lautréamont, I bsen etc.), à sombra dos quais molda sua imagem de artista, procurando ao mesmo tempo dissolver, com a marca de seu estilo, a periculosidade dos decadentes e revelar o empreendimento de aristocracia espiritual que estes levavam a cabo e que é, também, o seu próprio ("gostavam do bom vinho e eram pouco afeitos às carícias da deusa M orfina; [...] preferiam beber em copos, como os mortais comuns, a beber no crânio de seus avós; e..., à noite, em vez de irem à celebração dos diabos e das bruxas, trabalhavam"5).

A busca do refinamento da sensibilidade por meio da sensação e da percepção, depurada pelo trabalho com a sugestão, alimentava o sonho e a fantasia, criando novos espaços para o imaginário social - para a intimidade, para o "reino interior" -, assim como alentava o prazer e o erotismo, fazendo da energia sexual o princípio diretor do universo. Em franca dissidência com discursos provenientes de outras perspectivas ideológicas ou estéticas, $D$ arío defendia as possibilidades que a palavra contém quando não é submetida a estatutos al heios a ela, atitude que expressa tal vez significados de larga tradição, que fazem do poeta um protagonista do conhecimento. Tal atitude está presente em inumeráveis exemplos, especialmente no poema filosófico "El coloquio de los centauros" e em quase todos os incluídos na segunda edição de Prosas profanas. Essa convicção é ofuscada mais tarde nas dúvidas dos noturnos e em "Lo fatal", de Cantos de vida y esperanza (1905), e em El canto errante (1906), obras que, porém, sempre ressaltam a significação intelectual de seus textos.

O stextostambém satisfazem, especial mentea partir dosanos deresidência em Buenos Aires, sua convicção na necessidade de respal dar uma sólida rede continental, já estimulada por al guns periódicos e pelas revistas literá- 
rias dos modernistas (Azul, La Revista de América, Cosmópolis, El M ercurio deAmérica etc.), que propiciavam uma confraria hispano-americana, acentuada por dedicatórias, prólogos eartigos quetematizam osmembros.

É importante salientar que se tratava de uma tarefa intelectual praticamenteúnica por sua persistência no tempo eque, distanciando-se das concepções essencialistas, dedicava-se à difusão da cultura dos países latinoamericanos, articulando seus legados e laços concretos. O s constantes artigos a respeito evidenciam isso. Em relação a esseaspecto, épreciso ressaltar um objetivo que mesmo hoje não foi obtido: refiro-meà insistente defesa do lugar do espanhol no concerto de idiomas do 0 cidente, defesa que inclui 0 apoio às reivindicações apresentadas, no plano internacional, por intelectuais e homens de ciência.

A essa atividade somava-se o fato de que os primeiros modernistas morreram jovens. Essas mortes precoces e trágicas proporcionaram ao movimento um importante capital simbólico, provendo-o de heróis - "mártires da arte" - , circunstância que deu ao grupo uma espessura inesperada e colaborou com sua coesão. 0 "pai M artí" e o "irmão C asal" sustentavam as filiações da família modernista e deixaram como herança modelos do "apostolado do poeta".

o modernismo construiu, de forma eficaz, um território próprio no plano concreto esimbólico, estendendo, para isso, uma redequeajudava os autores a enfrentar a censura e o peso dos dirigentes políticos, do pensamento positivista (inimigo das concepções acerca do gozo dos sentidos ou do conhecimento surgido do universo sugestivo, "impreciso"), e a suportar o trabalho com a palavra, assim como a evitar a pressão religiosa das elites sociais e culturais dominantes e a sustentar a divergência com as perspectivas, fundamentalmente nacionais, de realistas e naturalistas. A lógica da amizade prevalecia sobre as dissidências grupais - eles disputavam, mas conviviam - , especialmente quando careciam, em seus países de origem, de instituições capazes de sustentar as práticas, como se dava com Silva ou o próprio $D$ arío: este último se apoiava não só nos contatos e na difusão pela imprensa, mas na edição contínua de suas obras, sobretudo quando correspondente de La N ación na Europa (quase nenhum escritor significativo da época conseguiu tais feitos).

Recordemos que, em termos gerais, os modernistas emigraram, por períodos mais ou menos extensos, às cidades modernas nacionais ou estrangeiras em busca de horizontes mais propícios às suas práticas artísticas. Para alguns essa situação se tornou definitiva, seja em razão do exílio - caso de 
6. Título de sua crônica em La Nación, 6 de outubro de 1912.
7. Literalmente: "E retornei a Paris. Retornei ao inimigo/terrível centro de neuroses, umbigo/ da loucura, foco de todo surmenage/ onde desempenho bem meu papel desauvage/ encerrado em minha cela na rue $M$ arivaux,/ confiando apenas em mim e resguardando o eu" (N.T.).
M artí ou de Vargas Vila - , seja porque não renunciaram à intervenção em dimensões mais amplas. D arío e G ómez C arrillo foram casos extremos desse distanciamento em relação ao pequeno mundo natal. 0 deslocamento dariano foi, nesse sentido, radical, já que, embora iniciado na adolescência, a N icarágua nunca deixou de ser um objeto privilegiado de sua produção poética e intel ectual: é certo que ele não buscava na terra natal seus pares ou seu público, mas ocasional mente retornava a ela. D arío não foi um exilado nem um imigrante, mas um migrante que não se estabeleceu de forma definitiva em nenhum lugar, um estrangeiro que muitas vezes experimentou a discriminação.

0 ceticismo reiterado desvanece o juvenil "El deseo deParís", ${ }^{6}$ que narra a viagem a um centro que, nos últimos anos, D arío insistia em apresentar como hostil e indiferente às penúrias dos imigrantes de fala espanhola. 0 texto contém uma peregrinação dolorosamente marcada pelas implicações que o enganoso rótulo de viagem estética oculta, além das constantes reflexões sobre a condição do artista moderno, temas presentes no extenso poema "Epístola a la Sra. de Lugones":

\section{Y me volví a París. M e volví al enemigo \\ terrible centro de la neurosis, ombligo \\ de la locura, foco de todo surmenage \\ donde hago buenamente mi papel de sauvage \\ encerrado en mi celda de la rue M arivaux, \\ confiado solo en mí y resguardando el yo ${ }^{7}$.}

Esse mote assume distintas significações nas reflexões darianas e, sem dúvida, define o território particular que os intelectuais construíam para si mesmos, no interior do qual D arío aconselhava, opinava, discutia, ironizava ou escandalizava, apoiando-se também na ampla tradição a respeito do enriquecimento do conhecimento graças à errância, tradição que a modernidade alimentava com os valores do cosmopolitismo e do universalismo. Essa atitude legitimava seu diálogo com um vasto mundo letrado, modulando distâncias em relação a ele, zombando ou discutindo concepções estreitas, respondendo de forma indireta ou aberta às críticas (a Unamuno, a Clarín, a Rodó, e muitos outros). M ediante diversos gestos imaginários, por vezes ficções de notável audácia, D arío configurou assim o al cance simbólico de sua consagração: no conto-crônica "H istoria de un sobretodo", publicado em 1892, refere-se ao casaco que comprou no C hi- 
le e que, já velho e gasto, acaba por proteger Paul Verlaine do frio; em outro conto, "H uitziloploxtli", publicado em 1915, no final da vida e de caráter autobiográfico, elabora sua imagem de exceção entre os intelectuais da época, pois surge compartilhando o acampamento de Pancho Villa e os al ucinógenos.

C reio necessário levar em conta, além disso, que uma das conseqüências dessa peregrinação, entre outros traços com os quais construiu a própria imagem, foi alimentar o mito de $\mathrm{D}$ arío como o poeta moderno hispanoamericano, conforme as caracterizações feitas por Roberto Arlt, Vallejo, Juan José Saer, Efraín H uerta etc.

Para introduzir outros aspectos, mas ainda apoiados no perfil que traçamos de $D$ arío como intelectual-artista, convém aproximarmos duas reflexões, aparentemente contraditórias. Em primeiro lugar, a deTulio $\mathrm{H}$ al perín D onghi, sobre os efeitos do estilo de $D$ arío:

Sua intuição de poeta Ihe dá acesso a uma compreensão privilegiada do processo histórico. Ele se alarma diante da guerra que se aproxima, presságio de nova derrota de uma França que, de forma frívola, repudia sua condição de primogênita da I greja; desafia, em nome de uma H ispano-América índia e latina, a Roosevelt, rude representante da outra América, bárbara e violenta; e, quando a guerra finalmente eclode, invoca uma América unida de norte a sul sob o símbolo da paz. 0 que $D$ arío assim oferece pode ser a tradução em verso sonoro dos editoriais lidos durante a manhã; essa operação confere a esses lugares-comuns uma verdade e profundidade novas, aos seus olhos e aos de seu público (D onghi, 1987, p. 61).

Em segundo lugar, a reflexão de Iris Z avala, que enfatiza o caráter inquisitivo que predomina nos artigos de $D$ arío, no momento em que 0 escritor tentava responder às perguntas que articulam uma perspectiva específica para o aqui e o agora: "O que é 0 americano? 0 que é 0 moderno? C omo chegar à modernidade? Q ual a função da arte? Q uem são os modernos? Q ual éo triunfo de Calibán? O quesignifica o novo americano? 0 que representa o crepúsculo da Espanha?" (Zavala, 1989, p. 9).

D arío pensou e expôs esse aqui e agora respaldado por Buenos Aires, emblema do progresso e do cosmopolitismo hispano-americano, cosmopolitismo compartilhado, nessa cidade que sente como sua, com os numerosos imigrantes estrangeiros ("afrancesados" eimigrantes), considerados uma ameaça à pureza do castel hano por vários integrantes das elites intelectuais e políticas criollas e espanholas. D arío chamaria tais elites de "patriotas da 
8. Em LaNación, 20 de outubro del899, incluído em España contemporánea (1901). consoante", amantes do "amor pátrio gramatical". Ele polemizava, emitia juízos, propostas, ediscursava de forma franca e explícita, apoiado em coloquialismos, usando alusões e simbologias clássicas ou modernas, com forte recorrência de vozes e citações em língua estrangeira - que desconcertavam os intelectuais mais compreensivos, como Valera ou Unamuno. Além do uso lexical livre, são vários os artigos dedicados à defesa do espanhol americano, como neste célebre fragmento de España contemporánea (1901):

O s glóbulos de sangue que carregamos, a língua, os vínculos que nos unem aos espanhóis não podem realizar a fusão. Somos outros. A té mesmo no intelectual, até mesmo na especialidade literária, o sabre de San M artín desencadernou um pouco o dicionário, rompeu um pouco a gramática. Isso não impede que tendamos à unidade no espírito da raçå ${ }^{8}$.

Essa independênciaéo fundamento desua postulação da unidadecultural latino-americana, pensada como a afirmação dos laços com a Espanha e com as nações que se consideravam herdeiras da cultura latina, laços em estrita relação de igualdade, sem tutelas. M ais ligado ao campo das idéias, 0 livro mencionado acima éum exemplo significativo da atividadeintelectual deD arío, impregnada, como sempre, por suas obrigações de correspondente, já que fora enviado à Espanha por La N ación para abordar os efeitos da perda, por parte desse país, das últimas colônias na América - Cuba, Porto Rico eFilipinas-, no final de 1898. A variedade demaneiras utilizadas para fazer referência à atualidade se mesclava com análises destinadas a revisar suas convicções eas dos intelectuais americanos do momento, convertendo assim a crônica em um fragmento da interpretação dos problemas geraisque o estimulavam. Essa atitude está presente em textos aparentemente orientados apenas pelas obrigações de correspondente. Em visita ao Palacio de la Exposición, por exemplo, os quadros são uma ocasião para $\mathrm{D}$ arío criticar as guerras, um dos eixos que estrutura España contemporánea. Partindo dos sentidos sociais da indiferença do público edos pintores pelos temas, $D$ arío trata da guerra em Cuba e introduz reflexões a respeito da paz mundial:

Entre todos os quadros desta exposição, com exceção de uma cena de hospital militar que retrata as conseqüências sentimentais da campanha militar, não há nada que pondere a história recente de humilhação e de esquartejamento da pátria. Isso tem uma explicação clara. A guerra foi obra do governo. 0 povo não queria a guerra, pois considerava as colônias apenas como terras para enriquecer 
os protegidos do governo. A perda delas não teve uma repercussão profunda no sentimento nacional (D arío, 1900).

D arío assim se revelava, sem dúvida, como um liberal republicano, cauteloso no plano estritamente político e social, sem se desviar ou ocultar os aspectos negativos, embora recorresse, muitas vezes, ao testemunho espanhol ou reiterasse o tom cauteloso de suas investigações, para expressar 0 chamado a essa Espanha que deve entender a crise como momento privilegiado de auto-análise e superação. 0 papel quenesse sentido atribuiu à cultura eà arteorientou seu interessee sua crítica ao provincianismo, à paralisia das instituições e da educação, à quase ausência de profissional ização e de um mercado moderno.

0 colonialismo repercutia de diversas formas em suas crônicas: ingresso por meio de uma referência que tangencia o tratado ou é seu núcleo, como em "Audrianamantra mby an trano" ${ }^{\prime \prime}$, cujo enigmático título, repetido no começo e no final, introduz a história de uma princesa malgaxe, "destronada de forma completamente progressista"; D arío denuncia então o "bárbaro" colonialismo europeu na C hina, na África e na América, denúncia reiterada ao considerar a guerra dos boers.

Esses textos, cujo tom se acentuou depois de 1898, são motivados pela preocupação com o destino da $\mathrm{N}$ icarágua e da América Central diante da ameaça representada pelo avanço político e cultural dos Estados U nidos. "O fato é" - afirma em "La invasión anglosajona" - "que em um tempo não muito distante a terra em que nasci [...] passará a ser uma dependência da grande república do norte; o restante da América Central o será depois [...]" (D arío, 1902). Ele temia e admirava a força dos Estados U nidos, definido prematuramente como Calibán em Los raros, tanto em razão do perigo concreto de ocupação de territórios latino-americanos como pelos efeitos na cultura desses países. U m dos pontos culminantes dessa atitude é a leitura de "Salutación del optmista" (1905), pouco antes da publicação de Cantos de vida y esperanza. 0 poema "A Rossevelt", de 1904, por outro lado, uma reação à intervenção norte-americana no Panamá, havia celebrado a força do caçador, do sportman que mira com ironia e que, nos artigos desse período, é definido com um "Rossevelt de rifle e pena". Com esses textos como contexto, lê o muito criticado poema de circunstância "Salutación al águila" (1906), exaltação da força dos Estados U nidos, que mostrava claramente as debilidades e contradições de $\mathrm{D}$ arío ao enfrentar o trabalho diplomático.
9.Em La Nación, 7 de julho de 1901. 
O s artigos sobre esse tema prosseguiriam nos últimos anos de sua vida.

10.Em La Nación, 28 de setembro de 1912.

11. A últimacrônicasobre o tema, de 15 de fevereiro de 1915, “Una cuestión dederecho internacional", comenta um texto de Rafael M onúfar, contrário à aquisição de terras pelos Estados Unidos para ba ses navais na Guatema la, onde $D$ arío desembarcou em 20 de abril, quando rumava para sua terra natal e para a morte.
Em "El fin de N icaragua"10, escrito após a revolução mexicana, denuncia a intromissão dos Estados U nidos nela, concluindo com os riscos da anexação de Cuba, Panamá e, certamente, da N icarágua ${ }^{11}$.

No final do século XIX, D arío passou a introduzir outra questão, de qual quer forma vinculada à anterior: a intervenção nas concepções do "Iatino-americanismo", que ele elaborou apoiando-se nos novos laços de solidariedade e união, é mais matizada do que as anteriores, que envolviam a Espanha e a América. Alguns notáveis artigos críticos - sobre Zola, G orki ou Antonio $M$ achado, entre outros - evidenciam o significado que atribui à função social da literatura, tema abordado também em seus poemas Cantos de vida y esperanza é o melhor exemplo. D e sua residência na Europa, acentuava-se, al ém disso, o recurso à argumentação, entreoutrasinflexões que reduzem a distância em relação a um discurso mais intelectual, inflexões que estão ligadas às mudanças em seu pensamento a respeito do desvanecimento da potência do artista, a potência do Poeta com $\mathrm{P}$ maiúsculo, que D arío atribuía a si mesmo e não renunciava a representar. Essas últimas questões singularizam e tornam mais complexo o itinerário dariano, caracterizado, em boa parte de sua trajetória, pela firme distância em relação a uma eoutra condição, de poeta (artista) eintelectual. É justamenteisso que torna importante considerá-lo da perspectiva da história intelectual, caso contrário dissocia-se em conteúdos e condutas 0 amálgama entre os dois discursos e as duas configurações presentes na figura do intelectual-artista.

\section{Referências Bibliográficas}

D ARío, Rubén. (1894), “Los raros. Filósofos finiseculares: N ietzsche”. La Nación, 2 de abril.

. (1900), "Algo de arte: certámenes y exposiciones". La Nación, 1o de maio. (1901a), “Audrianamantra mby an trano". La N ación, 7 de julho. . (1901b), España contemporánea. Paris, Garnier. . (1902), "La invasión anglosajona”. La Nación, 23 de abril. (1912a), "El deseo de Paris". La Nación, 6 de outubro. (1912b), "El fin de N icaragua”. La N ación, 28 de setembro. (1952), Los raros. 1a edição 1896. Buenos Aires, Espasa Calpe.

DongHI, Tulio Halperín. (1987), El espejo de la historia: problemas y perspectivas latinoamericanas. Buenos Aires, Sudamericana. 
GaLtieR, Lisandro Z. (1973), Carlos de Soussens y la bohemia porteña. Buenos Aires, M inisterio de Cultura y Educación.

N ÁjerA, M anuel Gutiérrez. (1881), "La protección a la literatura”. El Nacional, 15 de março.

Rama, Ángel. (1985), Las máscaras democráticas del modernismo. M ontevidéu, Fundación Ángel Rama.

Zavala, Iris. (1989), "Introducción". In: D aRio, Rubén. El modernismo y otrosensayos. M adri, Alianza.

\section{Resumo}

O intelectual modernista como artista: Rubén Darío

Este artigo revisa a trajetória intelectual de Rubén $D$ arío, perfilando a configuração do artista no modernismo (1880-1910), primeiro movimento concreto entre os escritores hispano-americanos, que renova substancialmente a produção literária em língua espanhola. Incorporado ao mercado moderno como jornal ista na condição de migrante, oriundo do contexto cultural arcaico da $\mathrm{N}$ icarágua natal, até os mais destacados centros hispano-americanos (Buenos Aires) e europeus (M adri, Paris), são consideradas suas demandas de autonomia estética e sua constante afirmação da autoridade do poe ta para intervir nas discussões sobre a sociedade e a cultura moderna. Aí se destaca sua aposta na criação de uma América Latina fundada em novos laços de solidariedade e união com a Espanha, diante do avanço ameaçador dos Estados U nidos. Palavras-chave: M odernismo; Artista moderno; Autonomia e mercado; M igrante.

\section{Abstract}

The modernist intellectual as artist: Rubén Darío

This article reviews the intellectual career of Rubén $D$ arío, profiling the artist's position in modernism (1880-1910), the first concrete movement among $\mathrm{H}$ ispano-American writers, which substantially renewed the literary output in Spanish. Incorporated into the modern market as a journalist and immigrant, thearticlefollows $D$ arío's intellectual life from the archaic cultural context of his native $\mathrm{N}$ icaragua to some of the foremost $\mathrm{H}$ ispano-American (Buenos Aires) and European (M adrid, Paris) centres, and considers his demands for aesthetic autonomy and his constant affirmation of the poet's authority to intervene in discussions relating to modern society and culture. Here we see the emergence of his commitment to the creation of a Latin America founded on new ties of solidarity and union with Spain, in the face of the threatening advance of the $U$ nited States.

Keywords: M odernism; M odern artist; Autonomy and market; M igrant.
Texto recebido em 13/ 3/2007 eaprovado em $13 / 3 / 2007$.

Susana Zanetti é professora-titular de Literatura Latino-americana da Universidade Nacional de La Plata e professora associada da Universidade de Buenos Aires. E-mail: susanaezanetti@yahoo. com.ar. 